\title{
SIMBOLISMO DE AGUA EN EL CINE: ENTRE EL ORIENTALISMO POÉTICO RUSO Y EL CATASTROFISMO OCCIDENTAL
}

\section{SYMBOLISM OF WATER IN THE CINEMA: BETWEEN RUSSIAN POETIC ORIENTALISM AND WESTERN CATASTROPHISM}

\section{Resumen:}

La representación de agua en las artes visuales tuvo siempre una potente carga simbólica que se nutrió de las tradiciones religiosas y filosóficas de todo el mundo. En función del contexto cultural, este elemento puede hacer referencia a la idea del nacimiento, a la búsqueda espiritual, al subconsciente, a la vía que une el mundo de los vivos y los muertos, etc. La aparición del cine, como un género que da vida a una imagen fija, proporciona al artista la posibilidad de explorar la totalidad de las posibilidades expresivas de las "aguas que corren" convirtiéndolas en un recurso visual recurrente en las obras cinematográficas de todo el mundo. En este artículo ofrecemos un estudio de la presencia acuática como argumento plástico y simbólico en el cine, centrando nuestra atención sobre todo en el análisis comparativo de las producciones rusas y occidentales. En este sentido, las primeras ofrecen un simbolismo acuático afine a la tradición oriental y las segundas se decantan por la línea del catastrofismo.

\author{
Anna Borisova \\ Universidad de Murcia (España) \\ anna.borisova@um.es
}

\begin{abstract}
:
The representation of water in the visual arts always had a powerful symbolism that was nurtured by religious and philosophical traditions all over the world. Depending on the cultural context, this element can refer to the idea of birth, to the spiritual quest, the subconscious, the road linking the world of the living and the dead, etc. The emergence of cinema as a genre that gives life to a still picture, gives the artist the opportunity to explore expressive possibilities of the "flowing waters" making a visual recurring resource in cinematographic works all over the world. In this article we provide a study of aquatic presence as symbolic and plastic argument in the film, focusing our attention mainly on the comparative analysis of Russian and Western productions. In this sense, the firsts offer aquatic symbolism tune to the Eastern tradition and the seconds opt for the line of catastrophism.
\end{abstract}

\section{Palabras clave:}

Agua; cine; búsqueda espiritual; oriental; occidental; modernidad líquida.

\section{Keywords:}

Water; Cinema; Spiritual Search; Eastern; Western; Liquid Modernity.

Este artículo forma parte de la actividad investigadora realizada en el marco del Departamento de Bellas Artes de la Universidad de Murcia (grupo Arte y políticas de la identidad). El proyecto fue financiado por la beca de la iniciación a la investigación de la Universidad de Murcia. 


\section{Introducción}

El video es un medio artístico cuya esencia es el movimiento. No es de extrañar que el agua, como elemento visual que evoca el dinamismo, llame la atención de los cineastas desde los comienzos de la historia del género. El investigador italiano $\mathrm{D}^{\prime}$ Aloia argumenta así la fascinación del cine por la superficie líquida:

The surface of the water inevitably refers to the surface of the cinematic screen. As water appears on the screen, one surface cuts another. Water makes the screen a fluid and interconnecting threshold between two places, between here and there, between present and past, conscious and unconscious, waking and sleeping, life and death. Just as the screen both separates and brings together the fictional and the actual world, water is also a plane of separation and connection between two different but not incompatible worlds ${ }^{1}$ (D'Aloia, 2012, p.100).

Los primeros cineastas aprovecharon los paisajes naturales con medios acuáticos como escenarios de belleza y expresividad extraordinaria para el desarrollo de sus tramas fílmicas. Durante sus primeras décadas el cine se deleitaba de la versatilidad de la imagen en movimiento, del poder sobre el tiempo y el espacio que proporcionaba el montaje y la elección del plano. Sin embargo, en los años 20 del siglo pasado, de la mano de los cineastas franceses se perfila una nueva perspectiva del género cinematográfico como una forma de lenguaje visual. Comienza la exploración intensa de las posibilidades expresivas de agua como elemento plástico y simbólico que no termina de concluir hoy en día. El conjunto de los significados del elemento se nutre de las múltiples tradiciones religiosas, filosóficas y artísticas de la historia dependiendo del entorno cultural de la producción cinematográfica en cuestión y del contenido de la reflexión que se plantea en el filme.

\footnotetext{
1 "La superficie del agua se refiere inevitablemente a la superficie de la pantalla cinematográfica. Cuando aparece agua en la pantalla, una superficie corta otra. El agua hace que la pantalla adquiera fluidez y conecte el presente y el pasado, el consciente e el inconsciente, el sueño y la vigilia, la vida y la muerte. Al igual que la pantalla que separa y une la ficción con el mundo real, el agua también forma un plano de la separación y conexión entre dos mundos diferentes pero no incompatibles" (la traducción es nuestra).
} 
Asombra la cantidad de las interpretaciones posibles, no obstante se observa claramente una línea de unión entre diversas tradiciones.

En este artículo pretendemos revelar principales enfoques de la cuestión mostrando las diferencias y similitudes en la representación del agua como uno de los recursos simbólicos en la producción fílmica y buscando las raíces de las mismas en las tradiciones culturales oriental y occidental.

\section{Marco teórico}

Sin duda, agua es uno de los elementos más enigmáticos y fascinantes que ha conocido la humanidad. Su presencia trae la abundancia y la vida y su ausencia conduce a una muerte inminente. Desde el alba de la humanidad las fuentes de agua fueron veneradas como los lugares donde habitan los Dioses o como divinidades en sí. Los antiguos maya convertían los pozos de agua subterránea en lugares de culto; para los egipcios el río Nilo constituía un camino entre el mundo de los vivos y él de los muertos. En las Antiguas Grecia y Roma abundan los mitos relacionados con el medio acuático: los dioses que viven o nacen de las aguas, como Poseidón o Neptuno, Afrodita o Venus, las historias de Narciso y Ulises. En el hinduismo toda agua es sagrada como una sustancia purificadora de los pecados del mundo. De aquí el ritual del baño en el río Ganges y su rol en las ceremonias fúnebres como la vía que lleva el alma del difunto al cielo. Los planteamientos parecidos ofrecen el Islam y el Budismo, relacionando el agua con la vía espiritual del crecimiento interior.

A su vez, el Antiguo Testamento ofrece la interpretación del elemento que asume la tradición cristiana. La mención de agua aparece en la descripción de los momentos anteriores a la creación del Universo: "Y la tierra estaba desordenada y vacía, y las tinieblas estaban sobre la faz del abismo, y el Espíritu de Dios se movía sobre la faz de las aguas" (Génesis 1 - 2). De esta manera, según la tradición judío-cristiana, agua es un elemento primario, una sustancia que presencia la creación del mundo. Asimismo, en el Cristianismo el ritual del bautismo se realiza por medio del sumergimiento 
en el agua como símbolo de la purificación y del nuevo nacimiento. Mircea Eliade resume así el significado religioso del elemento en cuestión:

Principio de lo indiferenciado y de lo virtual, fundamento de toda manifestación cósmica, receptáculo de todos los gérmenes, las aguas simbolizan la sustancia primordial de la que todas las formas nacen y a la que todas las formas vuelven por regresión o por cataclismo (Eliade, 1974, p. 222).

Hablando del acontecimiento destructivo, el historiador hace alusión al mito del Diluvio presente en muchas culturas: relata una inundación total de la Tierra como castigo divino a la humanidad por sus pecados. En el relato bíblico agua se convierte en un elemento que prueba la inocencia de nuestro ser ante la divinidad y trae, según el resultado, la purificación o la destrucción inminente. Sin embargo, no se trata de una visión pesimista del futuro de la humanidad, sino de la renovación constante de su propia esencia. Como lo explica Eliade:

(...) "vista" desde el plano neptúnico, la vida humana aparece como algo frágil, que tiene que ser reabsorbido periódicamente, porque el destino de todas las formas es disolverse para poder reaparecer. Si las "formas" no se regeneraran por su reabsorción periódica en las aguas, se desharían, se agotarían sus posibilidades creadoras y se apagarían definitivamente (Eliade, 1974, p. 246).

Todas las enseñanzas religiosas y filosóficas mencionadas presentan una reflexión sobre la relación entre el hombre y la naturaleza cuyo poder aterroriza y fascina, provoca respeto o ganas de luchar contra el destino predeterminado. Estas divergencias en el simbolismo de agua se deben a las particularidades culturales del entorno inmediato y se perciben claramente en los espacios de las cosmovisiones tan distintas como Oriente y Occidente.

En este punto de la investigación se hace necesario definir las nociones que delimitan las zonas culturales que estamos nombrando. Generalmente, existe cierta confusión en cuanto a los términos de separación entre el Oriente y Occidente. Históricamente hablando, la primera división del mundo entre Europa y Asia surgió en la Antigua Grecia debido al desconocimiento sobre los límites reales de los continentes. A posteriori, a pesar de descubrir la ausencia de los motivos geográficos de la delimitación propuesta, ésta se 
quedó arraigada en las mentes de los contemporáneos aludiendo a la disociación entre la civilización desarrollada a partir de la cultura de Egipto, Sumeria y Antigua Grecia (Europa Cristiana Occidental) y el resto del mundo. Por consiguiente, este planteamiento se defiende en términos religiosos y sus derivados culturales y sigue empleándose hoy en día con algunas modificaciones. La cosmovisión occidental se asocia habitualmente con la tradición cristiana, aunque actualmente también hace alusión a la homogeneización del mundo bajo el paradigma del modo de vivir estadounidense. En este sentido, existen varios países que según la interpretación del término entran o no en la categoría occidental, entre ellos Rusia. A pesar de que es un país donde la religión cristiana es predominante, Rusia histórica- y geográficamente se encuentra en medio entre las tradiciones culturales oriental y occidental, nutriéndose de ambas cosmovisiones. A su vez, el periodo de la existencia de Unión Soviética con su ateismo y las divergencias políticas e ideológicas con el Occidente, consiguió declinar la balanza hacia la tradición oriental, lo que se reflejó en la producción cinematográfica del momento. La simbología creada como el resultado, se arraigó y hoy en día se presenta como una línea de creación predominante dentro del cine ruso.

Hay que mencionar que las civilizaciones de Oriente bajo sus tradiciones religiosas principales desarrollaron una noción de la naturaleza basada en el respeto filial. El ser humano se percibe a si mismo como una parte del universo vivo ni más perfecto ni más importante que otras creaciones de la divinidad. De esta manera, cualquier intervención agresiva en el entorno natural se considera un delito contra uno mismo y contra Dios. La sociedad debe encontrar la forma de convivir con todo lo que le rodea, aprender de ello y mostrarse respetuoso ante cualquier percance provocado por las fuerzas de la naturaleza ya que estas desgracias forman parte del orden establecido de las cosas.

En contraposición a la tradición oriental, en el Occidente el hombre es considerado como la creación cumbre de Dios, el único ser concebido a su imagen y semejanza según el Cristianismo. La Tierra y todo lo vivo es entregado al Adán como un regalo de Todopoderoso a su amada criatura: 
"Sean fecundos y multiplíquense. Llenen la tierra y sométanla. Tengan autoridad sobre los peces del mar, sobre las aves del cielo y sobre todo ser viviente que se mueve sobre la tierra" (Génesis 1-28). La percepción de la naturaleza como fuente de recursos destinados para el disfrute del ser humano se deriva en la actitud oportunista del hombre hacia su entorno. La situación se desemboca en un serio problema en el siglo XX cuando la industrialización alcanza altos niveles de desarrollo causando daños irreversibles al ecosistema planetario. En las últimas décadas el cambio climático pasa de ser una hipótesis científica a un hecho consumado y sus consecuencias en forma de desastres naturales no dejan de provocar terror en las sociedades actuales.

Los dos modelos de convivencia con el mundo circundante que hemos descrito forman base conceptual y simbólica para la creación artística derivada de cada una de las tradiciones culturales. También es importante mencionar que el proceso de la globalización deja su huella en la producción artística que comienza a barajar varias combinaciones entre las visiones existentes presentando simbología híbrida. Nos proponemos explorar las interpretaciones de agua que se presentan en las obras cinematográficas basando nuestro estudio en los ejemplos ofrecidos por el cine ruso que refleja la perspectiva de la tradición oriental y el cine occidental (sobre todo, estadounidense) con su versión catastrofista.

\section{Metodología y objetivos}

En el curso de presente investigación hemos estudiado las creaciones cinematográficas que evocan la presencia de agua atendiendo su tratamiento plástico, el papel que desempeña en la narrativa y la relación que establecen los protagonistas con este elemento. La selección de ejemplos fue realizada siguiendo el criterio del grado de implicación del elemento acuático en el relato fílmico. En este sentido, el agua tiene que presentarse como un hilo conductor de la historia o como un personaje imprescindible en la trama ofreciendo pistas que revelan el sentido de la obra cinematográfica. Desde luego, no podemos pretender abarcar toda la filmografía que incluye 
mencionado símbolo, pero sí intentamos discernir los ejemplos más representativos para el caso. De esta manera, pretendemos construir la semiótica de la simbología acuática en la obra fílmica. Asimismo, hay que mencionar que la metodología seguida en el transcurso de la investigación comprende los métodos más generales: sistémico, comparativo, semiológico e inductivo - deductivo.

Uno de los objetivos principales del presente ensayo consiste en establecer las pautas de la utilización del agua como símbolo en el cine relacionándolo con el contexto cultural de la creación cinematográfica. En este sentido, los ejemplos de películas elegidos se distribuyen en dos bloques que hemos denominado "orientalismo poético ruso" y "catastrofismo occidental" siguiendo las líneas de simbología adaptada por cada uno de los grupos presentados. Así se hacen patentes las divergencias entre las dos cosmovisiones que tradicionalmente se contraponen una a la otra: Oriental y Occidental.

Por último, para concluir nuestra reflexión, veremos algunos ejemplos de las obras cinematográficas cuya simbología acuática denota la hibridación cultural como consecuencia de los procesos de la globalización y la multiculturalidad.

\section{Exposición}

\subsection{Simbolismo de agua en el cine intelectual: la tradición Oriental}

Como hemos mencionado anteriormente, los planteamientos culturales que se asocian al orientalismo relacionan el elemento acuático con la vida espiritual. De este modo, los cineastas cuyas obras se inspiran en la tradición oriental evocan visualmente el agua en alusión a la vía hacia el crecimiento interior. El contacto con este elemento e, incluso, su contemplación permite establecer la conexión con lo divino y recuperar así la armonía de nuestro propio ser. Esta línea del visionario acuático comienza su desarrollo en las obras del cine vanguardista francés (la primera mitad del siglo XX), se reitera con más fuerza en los filmes de Andrey Tarkovsky a partir de los años 6o, 
llegando a su máximo en el cine ruso de las dos últimas décadas. A pesar de que la localización geográfica y la tradición religiosa de Francia y Rusia los sitúa más cerca de la cultura occidental, la búsqueda de nuevos caminos en el arte, junto con algunos acontecimientos históricos que influyen en el imaginario artístico, desplaza el foco de interés de los cineastas, que crean sus obras en el contexto cultural de estos países, hacia los planteamientos orientales.

Tras la Primera Guerra Mundial en Francia se dan los primeros pasos hacia la renovación del planteamiento del arte cinematográfico. El impulso hacia el cambio lo dan los intelectuales, como el novelista Louis Delluc y el teórico Ricciotto Canudo, que se dedican principalmente a la escritura, pero también muestran especial interés en explorar las posibilidades del Séptimo Arte. El nuevo movimiento vanguardista en el cine se inscribe dentro de la línea Impresionista trasmitiendo sus ideas por medio de un lenguaje visual depurado estéticamente y lleno del simbolismo. Gilles Deleuze define así el trasfondo de interés que muestran los artistas franceses por el agua como argumento de su obra cinematográfica:

No se trataba en absoluto de un renunciamiento a la mecánica, sino, por el contrario, del paso de una mecánica de los sólidos a una mecánica de los fluidos que, desde un punto de vista concreto, iba a oponer un mundo al otro y, desde un punto de vista abstracto, iba a encontrar en la imagen líquida una nueva extensión de la cantidad de movimiento en su conjunto: mejores condiciones para pasar de lo concreto a lo abstracto, una mayor posibilidad de comunicar a los movimientos una duración irreversible más allá de sus caracteres figurativos, una más firme capacidad para extraer el movimiento de la cosa movida (Deleuze, 1984, p. 69).

Entre las décadas 20 y 30 del siglo XX los directores Marcel L'Herbier, Jean Epstein, Jean Vigó estudian la riqueza visual del agua utilizando diversas herramientas: los filtros, la superposición de las imágenes, desenfoque, etc. En L'Atalante de Jean Vigó (1934) la corriente del río cobra un sentido simbólico en alusión a la vida y el amor. Inseparable de la semiótica de agua aparece aquí el bote como medio que posibilita el transito por la superficie acuática. Podremos ver la evocación de esta unión semántica en las obras 
cinematográficas posteriores una y otra vez. Si el agua es la Madre, la fuente de la vida, el bote en este caso representa la Matriz, el lugar de la transformación, del crecimiento.

A su vez, en la película Menilmontant de Dmitrii Kirsanov (1924) el estado psicológico inestable de la protagonista se trasmite visualmente por medio de la superposición de su rostro y la corriente del río donde ella tiene intención de suicidarse. Jean Epstein en Coeur Fidele fusiona las imágenes de una marea, la superficie de un río, las olas altas del mar durante una tormenta con las escenas que muestran momentos críticos en las relaciones de sus protagonistas. De esta manera, los cineastas añaden intensidad y un ritmo especial a la narrativa visual y sus piezas cinematográficas adquieren características del video arte tal, como lo conocemos hoy en día.

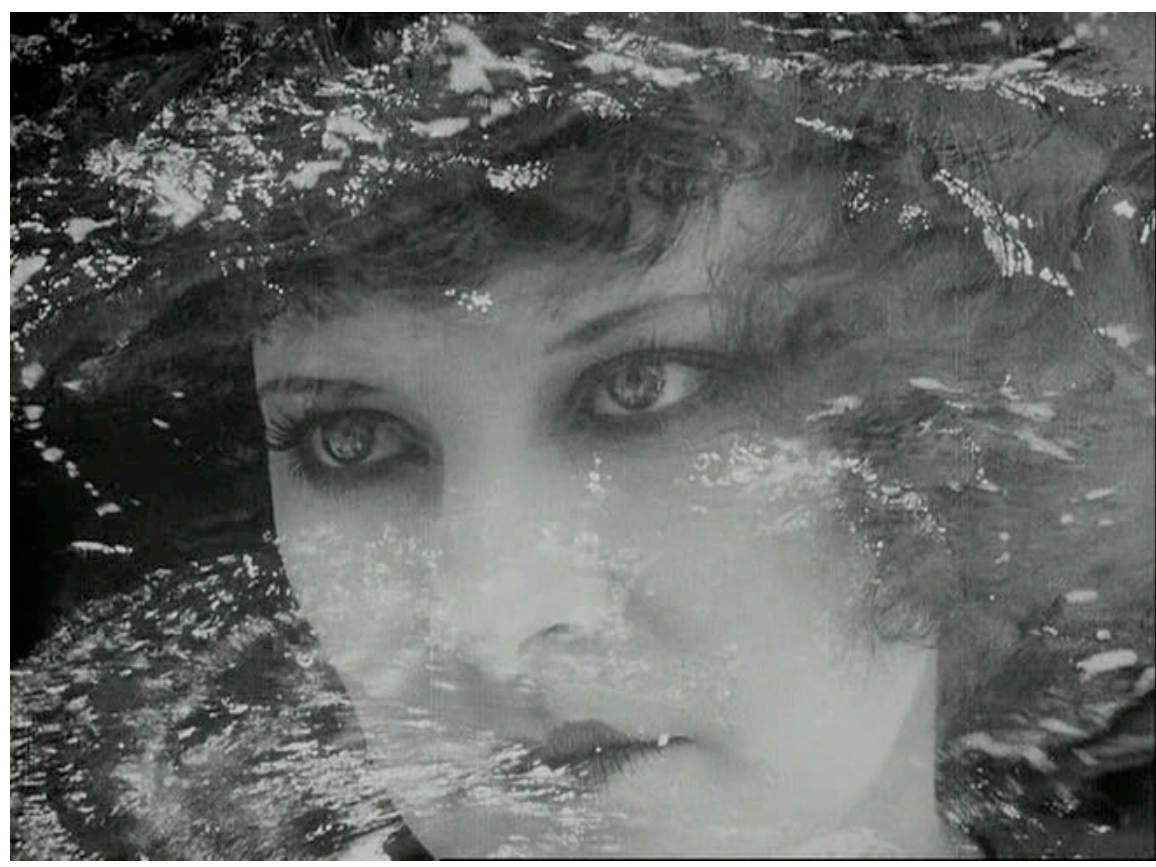

F 1. Fotograma de Coeur Fidele de Jean Epstein (1923) (imagen extraída de http://fromafog.blogspot.com.es/2010/12/trois-films-de-jean-epstein-coeur.html)

Al hilo de ello, es importante mencionar a L'Herbier que en el filme L'homme du large utiliza el mar como "un sistema perceptivo" (Deleuze, 1984, p. 116) capaz de transformar nuestra visión del mundo. De esta manera, se supera la utilización habitual de agua como un "objeto de percepción” (Deleuze, p. 116) traspasando la línea de la representación directa del elemento como 
escenario de los acontecimientos y atribuyéndole uno de los papeles principales en e la narrativa visual.

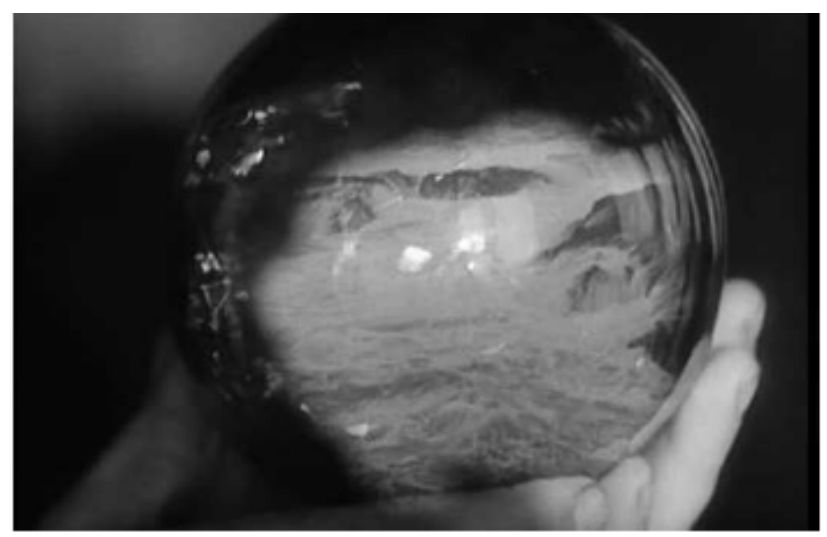

F 2. Fotograma Le Tempestaire (Epstein, 1947) (imagen extraída de http://membrane.tumblr.com/post/488317323/attendant-avec-le-corps-dans-la-barquetadg-mor)

Por otro lado, podemos nombrar a Jean Renoir como uno de los directores que predicó el realismo poético en el cine y lo practicó utilizando la simbología de la imagen. Desde su primera película este cineasta confiere una dimensión especial al agua en movimiento, a la relación entre el cuerpo y el líquido. En este sentido, la máxima expresión de su visión particular del espacio acuático aparece como argumento central en su película El río (1951) filmada en la India, país con una tradición muy arraigada de la veneración del agua. En esta obra Renoir trata de reflejar el paso del tiempo a través de agua que fluye por el río Ganges, a orillas del cual se rodó el filme. Las experiencias van y vienen, los personajes se inician en la vida adulta dejando atrás la inocencia y su transformación interior se discurre al ritmo de la corriente del agua que sirve de fondo para la acción fílmica conformando un hilo conductor de su narrativa.

En definitiva, nos parece muy acertada la observación de Deleuze sobre el movimiento cinematográfico descrito en cual afirma que los cineastas de la vanguardia francesa buscaban un nuevo sistema perceptivo basado en la noción líquida:

Finalmente, lo que la escuela francesa encontraba en el agua era la promesa o la indicación de otro estado de percepción: una percepción más que humana, una 
percepción que ya no se obtenía de los sólidos, para la que el sólido ya no era el objeto, la condición, el medio (Deleuze, 1984, p. 121).

Sorprendentemente, es en la Unión Soviética donde en los años 60 empieza su carrera un director que reitera las preocupaciones estéticas del cine intelectual francés creando un precedente único para el cine del país totalitario. La obra de Andrey Tarkovsky, desde mundialmente conocido Andrey Rublev hasta su última creación, Sacrificio, realizada en el exilio, presenta un simbolismo elaborado, un lenguaje visual tan expresivo como críptico. El líquido que difiere en sus características de densidad y transparencia aparece en todos los filmes de director. Vemos inundaciones, lluvias en los espacios cerrados, sustancias densas cuya superficie sufre una especie de metamorfosis constante. Agua en Stalker sobrepasa la calidad del símbolo y se convierte en un personaje que dialoga silenciosamente con los protagonistas determinando tanto el ritmo visual de la narrativa, como su línea del desarrollo semántico.

En Nostalgia la densa niebla sobre el agua inunda la atmósfera de la película creando un ambiente sofocante, insoportablemente confuso. Podríamos seguir y seguir ya que la abundancia de este elemento en la filmografía de Tarkovsky no deja lugar a dudas de que el director atribuye una gran carga simbólica al medio acuático, yendo incluso más allá del descentramiento perceptivo propuesto por los cineastas franceses. En opinión de Deleuze, la naturaleza del visionario de las aguas que construye Tarkovsky podría ser descrita en términos del proceso "metamorfosis por mezcla" que alude a un cambio interior provocado por las experiencias vividas. De esta manera, se intuye en la obra del cineasta ruso una reflexión vinculante a todos sus filmes: Tarkovky propone la búsqueda espiritual como camino hacia el encuentro con el propio "yo" del artista. Tatiana Bubnova sitúa la base de esta preocupación identitaria en las particularidades del desarrollo de la consciencia nacional rusa:

El hilo de la identidad, de la autobiografía intrínseca y de la autoafirmación mediante la creación se entreteje en el pensamiento del cineasta con ciertas posturas ideológicas afines a sus contemporáneos, quienes retomaban a su vez la estafeta de las tendencias de la cultura rusa -abandonadas o semiolvidadas 
durante el período soviético- del siglo XIX y anteriores. Así, en la obra de Tarkovsky aparece de una u otra forma un cierto mesianismo inherente a la convicción en la originalidad absoluta de los destinos históricos de Rusia, junto con las definiciones rotundas del carácter nacional. Aunque se trate de una marca generacional, no deja de estar profundamente personalizada y sus implicaciones jamás se manifiestan de una manera unidireccional y reductora, sino que permiten lecturas ambivalentes y polisémicas (Bubnova, 2003, p.53).

La cuestión identitaria en Rusia se agudiza durante la década de los 70 del siglo pasado mientras en el horizonte cultural se marca una clara fisura entre la cultura soviética oficial, fiel a las necesidades del estado totalitario, y la inconformista que pone en duda los mecanismos de la alineación ideológica utilizada por el aparato gubernamental. Muchos artistas e intelectuales rusos de la época del "deshielo" consiguen crear una red clandestina que genera y comparte una línea de pensamiento alternativo, libre de la ideología soviética. Durante los años posteriores se crea todo un conjunto de obras artísticas de contenido aparentemente inocente, pero con un mensaje crítico oculto tras la imaginería críptica. En este sentido, a pesar de que Tarkovsky no llega a confirmar que su simbología forma parte de un lenguaje visual con una segunda lectura en contra del régimen político, la trayectoria del desarrollo de su obra revela una tendencia clara hacia la codificación cada vez mayor del mensaje fílmico. El contenido de sus largometrajes participa de una línea del pensamiento claramente espiritual. En Andrey Rublev, por ejemplo, el director se aventura a evocar las imágenes y el discurso de la religión ortodoxa. Esta actitud le trae grandes problemas tanto para seguir con el rodaje de la obra en cuestión, como para conseguir su visionado en los canales oficiales. Varias escenas de la película son vetadas por el Comité de la censura y el director se ve obligado a replantear el montaje final recortándolas. A consecuencia, las obras posteriores de Tarkovsky muestran una narrativa visual altamente codificada y, a pesar de que en Stalker, por ejemplo, cita abiertamente pasajes enteros de la Biblia, la maquinaria burocrática no le pone ningún obstáculo y el visionado de la película se permite en todo el país. El género del filme se define como la ciencia ficción y como tal no se considera "sospechosa" desde el punto de vista ideológico. De 
esta manera, Tarkovsky, teniendo en cuenta la experiencia de su primer trabajo, se encarga de esconder el sentido real de sus obras posteriores tras una simbología visual críptica. Lo curioso es que a pesar de la negativa del propio director a revelar el significado de cada elemento, existe multitud de trabajos de la investigación que desglosa todos los símbolos utilizados en sus filmes.

La tendencia del imaginario líquido inherente a la cuestión identitaria que marca Andrey Tarkovsky en su obra se conserva y se desarrolla en el cine ruso durante las décadas posteriores a su muerte (1986) hasta nuestros días. En el horizonte político del país aparecen indicios de un cambio inminente que llega con la Perestroika de Mikhail Gorbachev a mediados de los 80. Las reformas propuestas por el Secretario General del Estado fracasan estrepitosamente provocando una profunda crisis económica, política y cultural. Finalmente, tras siete décadas de existencia, la Unión Soviética se desintegra en 1991, arrastrando consigo todo el aparato ideológico cuidadosamente elaborado con el fin de formar al ciudadano ruso como una tuerca perfecta para la maquinaria totalitaria. En ausencia de un nuevo punto de partida para la autodefinición nacional tras la desaparición de la referencia ideológica de URSS, se agudiza la cuestión identitaria para un ciudadano libre de las cadenas del totalitarismo. El arte se encarga de explorar posibles combinaciones de la subjetividad fragmentada y el cine, en este sentido, se presenta como una herramienta perfecta. Aparecen dos líneas claramente marcadas en la creación fílmica posterior a la Perestroika: el cine "Chernukha" (Graham, 200o) encargado de desmantelar el mito soviético presentando la cruda realidad social del momento y el cine intelectual (o poético), heredero de la obra de la vanguardia francesa y de Tarkovsky.

En el cine intelectual ruso la formula de la expresión visual de la identidad como concepto fluido frecuentemente se elabora evocando un medio líquido - aguas en movimiento, viajes por un medio acuático, lluvia, etc. Como un ejemplo perfecto en este sentido podemos mencionar las obras de los directores como Alexandr Sokurov, Andrey Zvyagintsev, Vladimir Khotinenko, Alexey Fedorchenko que acuden al simbolismo de agua en su discurso cinematográfico sobre la identidad rusa. 
El primero en tomar la estafeta de Tarkovsky como poeta del cine ruso fue Alexandr Sokurov, cuya carrera como director despega a finales de los 80 gracias a la política de la Apertura cultural promovida por Mikhail Gorbachev. La primera película que realizó este cineasta, La voz silenciosa de un hombre (1978), fue prohibida por la censura durante 10 años posteriores a su creación y tras salir a la luz en 1988 cosechó múltiples premios internacionales. El tema más recurrente en la obra cinematográfica de este director es la espiritualidad y la muerte. En este sentido, como contrapeso a la inestabilidad generalizada de la vida en Rusia tras la Perestroika, Sokurov propone la lentitud de la transformación de la imagen que parece casi estática en sus películas. Es una invitación a abstraerse del ritmo frenético del mundo circundante y dirigir la mirada hacia nuestro interior, buscando la identidad propia a través de la espiritualidad recobrada gracias a este ejercicio de autocontemplación.

El lenguaje fílmico que construye el cineasta muestra un simbolismo elaborado a nivel de la imagen y del sonido. En este sentido, la aparición de agua como argumento visual y sonoro suele tener relación con los momentos críticos que atraviesan sus protagonistas o, como es el caso de la Dolorosa indiferencia (Skorbnoe bezchuvstvie), constituye dimensión paralela a la realidad, otro sistema de percepción que acompaña la búsqueda del sentido existencial de los personajes. Asimismo, en Días de crepúsculo, Madre e hijo, Salva y protege las sensaciones del espectador son dirigidos en parte por la evocadora banda sonora compuesta por las conversaciones, gritos, susurros, canciones, plegarias en diversos idiomas, así como por los sonidos ambientales, como la lluvia, el chillido de los cuervos, el paso de un tren, el trueno de una tormenta que nunca estalla, etc., introducidos casi siempre en discordancia con los hechos que presenta la imagen fílmica. Si agua no aparece en el encuadre, la oímos y el efecto resulta aun más impactante.

En conclusión, se podría decir que la simbología de agua usada por Sokurov guarda parecido con el imaginario de Tarkovky a muchos niveles: igual que su antecesor este cineasta contemporáneo evoca elemento acuático en alusión a la búsqueda espiritual, a los cambios interiores que se producen a raíz del encuentro con una verdad superior. Asimismo, el director acude a la 
simbología del barco propia para la tradición francesa: este vehículo acuático sirve de guía en el camino de sus protagonistas hacia el reencuentro con lo espiritual. En este sentido, en el filme Madre e hijo como punto culminante del dolor que sufre el protagonista por la proximidad de la pérdida de su madre aparece una visión del barco en medio de un mar de la niebla. Este espejismo parece formar parte de los pensamientos del chico, un sueño que le trae un poco de consuelo. Presente simbolismo de la nave acuática se apoya además en las obras de los pintores como William Turner y Caspar David Friedrich.

En definitiva, el ritmo lento de los filmes de Alexandr Sokurov invita a la contemplación, un camino hacia la armonía del espíritu que se predica en el Oriente. Las aguas en su obra nunca llegan a ser violentas o amenazadoras.

Otro de los cineastas rusos en cuya obra el simbolismo de agua adquiere gran importancia es Andrey Zvyagintsev. Su filme más conocido, El regreso (Vozvraschenie) cuenta la historia del reencuentro de un padre con sus dos hijos, ya adolescentes, tras una larga ausencia del mismo. Para recuperar el tiempo perdido los tres emprenden un viaje que termina trágicamente con la muerte accidental del progenitor. A consecuencia, los dos chicos tienen que encontrar solos el camino de vuelta a casa llevando el cadáver de su padre para poder enterrarlo. Esta experiencia traumática los obliga a madurar muy deprisa.

Es importante mencionar, que Zvyagintsev construye la narrativa de su película evocando las imágenes con referencias claramente pictóricas y consigue de esta manera trasmitir incontables sensaciones y emociones más allá de la historia conmovedora. El elemento más recurrente en las escenas del filme es agua. Los protagonistas vuelven a entrar en contacto con ella una y otra vez: el chico que no consigue saltar al río desde la torre, los hermanos pescando, el viaje en el bote hasta la isla y, finalmente, el cadáver del padre hundiéndose en las aguas. Esta abundante "fluidez" del entorno nos obliga a reflexionar sobre la función simbólica del agua en el cine de Zvyagintsev y, teniendo en cuenta la temática del filme, plantear la relación de este elemento con el dinamismo de la identidad humana. La película relata el 
camino tortuoso hacia la madurez de los protagonistas y la vía de la transición descrita parece ser el agua. El conflicto generacional, salvando la interpretación directa, se traduce en el choque entre la rigidez del pasado soviético y la inestabilidad de los nuevos tiempos. Los tres protagonistas tienen su propia forma de enfrentarse al problema de la adaptación. El padre encarna una identidad sólida, cuya naturaleza inamovible, incapaz de adaptarse, lo lleva a la muerte. El hijo menor (Iván) representa una individualidad fluida, como el otro extremo de la realidad, y se enfrenta a la autoridad de lo rígido - no soporta la tiranía del padre y la desafía constantemente. El término medio personifica Andrey, el mayor de los hermanos. Se encuentra oscilando entre los dos extremos sin saber a que atenerse. Curiosamente, precisamente él dirige todo el camino de vuelta a casa movilizándose y asumiendo la responsabilidad en el momento difícil. El director, de esta manera, apunta a la idea de que cualquier estado llevado al límite es perjudicial y no puede tener futuro. ¿Sería su variante de la solución de la cuestión identitaria en Rusia?

En una categoría aparte nos gustaría mencionar el trabajo de Vladimir Khotinenko titulado Muslim (Musulmanin). La principal cuestión que preocupa al director es la espiritualidad auténtica y las diversas formas de disfrazarla hoy en día. La historia que cuenta el filme nos traslada al momento histórico posterior a la guerra de Afganistán, cuando liberan a un soldado, Kolya Ivanov, raptado por los afganos durante la operación militar. Tras años de cautiverio, Kolya es convertido al Islam. Su fe es tan profunda y sincera que sigue practicándola a pesar de volver a su tierra natal. Sin embargo, estas nuevas creencias lo enfrentan a los habitantes de su pueblo y, incluso, a su propia familia convirtiéndolo rápidamente en un marginado. Aún así, el chico sigue luchando por su fe a pesar de constantes insultos y palizas que recibe de su hermano mayor.

Uno de los puntos culminantes de la historia conforma el relato de una leyenda del pueblo sobre una iglesia que se encuentra hundida el fondo del río cercano. Si uno consigue hallarla y tocar la crucifixión que la encabeza, se queda libre de cualquier pecado. Varios de los personajes principales intentan hacerlo sin éxito, sólo el comandante de Kolya lo consigue y hasta 
desiste de su venganza tras la experiencia. Se observa una clara continuidad en la utilización del agua como representación simbólica de la transformación interior.

Por otro lado, para demostrar la eficacia del camino tradicional que sigue presuntamente la gente de la aldea en contraposición a la elección de Kolya, un vecino adinerado habla constantemente de la renovación, una mejora de la vida que nunca llega. El hombre basa sus expectativas sobre todo en los bienes materiales, pero recibe una lección cuando estando borracho se cae al río y el dinero que lleva en su maletín se dispersa por la corriente. A la mañana siguiente los habitantes del pueblo se tiran al agua para recoger el tesoro inesperado y lo llaman "maná del cielo". Se pelean por él asemejándose a una manada de animales salvajes. Como un detalle importante para el relato simbólico aparece un bote anclado en la tierra. Durante la recogida del dinero vemos en él a una de las campesinas, sentada con la mirada ausente y haciendo el gesto de remar en el aire. Seguidamente, Kolya y su asesino en la última escena hablan en proximidad de esta extraña aparición sin sentido. De nuevo el barco tiene clara relación con la idea de la búsqueda espiritual, aunque la misma no termina con éxito. De esta manera, una degradación espiritual en ausencia de la fe, de la moral fija a la cual atenerse, aparece en la película como la raíz de los problemas en Rusia. Como alternativa se presenta un intercambio cultural, un diálogo con el “Otro", pero a falta de la tolerancia hacia lo diferente parece un camino imposible. Por tanto, las perspectivas dibujadas por Khotinenko resultan bastante pesimistas -el protagonista no consigue reconciliarse con los suyos y es asesinado por uno de sus comandantes que lo considera traidor. No parece que para el director existe una posible solución a la situación actual en Rusia, los límites indefinidos de la identidad rusa no obtendrán forma hasta que el ciudadano deniega de su percepción de la espiritualidad como algo de quita y pon según las circunstancias y la conveniencia.

De esta manera, en la línea del cine intelectual ruso encontramos muchas obras que utilizan agua como seña de la vía espiritual en el camino de la reconstrucción identitaria. Se podría nombrar más ejemplos de las películas participes de este tipo de construcción del sentido simbólico, como Viaje con 
los animales domésticos de Vera Storozheva, Isla de Pavel Lungin, Souls in silence de Alexey Fedorchenko, etc.

En relación a ello cobra importancia la aparición del barco como símbolo del viaje interior hacia la redefinición del propio yo junto con la evocación del agua como símbolo de un nuevo nacimiento, del crecimiento espiritual, de la unión con la naturaleza, que tiene sus raíces en la filosofía de la autocontemplación como camino hacia la armonía interior.

En definitiva, hemos observado el tratamiento plástico y simbólico del elemento acuático en las obras cinematográficas que se inscriben en la línea del pensamiento oriental. En ellas las aguas se evocan en alusión al proceso de la construcción identitaria a partir de la armonía con el entorno natural y el núcleo espiritual. En este sentido, los filmes rusos acuden a menudo a la simbología de agua tratando el tema de la identidad y reflexionando sobre los variantes de un “yo” post-soviético.

\subsection{Catastrofismo del cine occidental: modernidad líquida o la identidad a la deriva}

En contraposición a la tradición oriental que predica la armonía con el entorno como el paradigma de la vida, el hombre occidental, como el centro del universo, pretende lidiar con las fuerzas de la naturaleza para conseguir los medios necesarios para su bienestar. Por consiguiente, podemos observar que los artistas que comparten esta cosmovisión interpretan el agua como una fuerza destructiva, como el símbolo de la fragilidad humana. Con una mirada superficial a la filmografía hollywoodiense es suficiente para darnos cuenta de la magnitud de esta preocupación. Las películas evocan catástrofes tanto hipotéticos, como reales presentando al ser humano enfrentado a las fuerzas naturales.

Así, en las películas como Deep Impact de Mimi Leder (1998), 2012 de Roland Emmerich (2009), Lo imposible de Juan Antonio Bayona (2012) apreciamos la potencia destructiva del agua y la fragilidad del ser humano ante la furia de la naturaleza. Waterworld de Kevin Reynolds (1995) muestra 
las consecuencias del cataclismo parecido al mítico Diluvio, un mundo donde reina el medio acuático imponiendo sus reglas al ser humano.

Asimismo, una metrópolis sumergida en las aguas profundas del océano aparece en Inteligencia Artificial de Stiven Spilberg (2001). Los contornos borrosos de los edificios, los objetos llenos de fango parecen crear un mundo paralelo a la realidad, un lugar lleno de los fantasmas del pasado. Es donde David, el protagonista del filme, espera encontrar a la Hada Azul, un ser mágico capaz de hacer milagros y convertir el robot en un niño humano. Agua que da la esperanza de la vida y la destruye, que es el origen de las civilizaciones y su trágico final.

En el caso de la producción de Spilberg, el director explora tanto el simbolismo de agua como la potencia visual del elemento. Observamos su integración en la imagen fílmica en calidad de una lente que distorsiona la realidad en la escena de la piscina donde tiene lugar el desafortunado incidente culpable del abandono de David. Los niños invitados a la fiesta deciden comprobar si David siente dolor y el chico-robot busca protección de Martín, el hijo de la pareja protagonista. Los dos niños caen a la piscina y el fuerte abrazo de David no permite que el otro salga a la superficie para respirar. Se quedan un rato en el fondo - un lugar que proporciona seguridad y protección al chico 'meca', pero supone una muerte por ahogamiento al niño humano. Finalmente los padres acuden a la ayuda de su hijo y David se queda sólo sumergido en el agua de la piscina. Varias veces se cambian los puntos de vista que ofrecen diversas percepciones de lo que ocurre. Vemos a David en el interior de la piscina, la posición de su pequeño cuerpo expresa la confusión y el miedo. La vulnerabilidad de su situación se ve potenciada visualmente con el recurso de la superposición de la rejilla fluida, compuesta por los reflejos de luz en el agua, sobre su diminuta figura en el fondo. Seguidamente se alterna la visión de los acontecimientos y observamos el exterior de la piscina desde el prisma acuático que distorsiona tanto la imagen como el sonido. De esta manera, la superficie líquida se convierte en una barrera infranqueable entre la realidad de un robot y las personas que interactúan con él. 

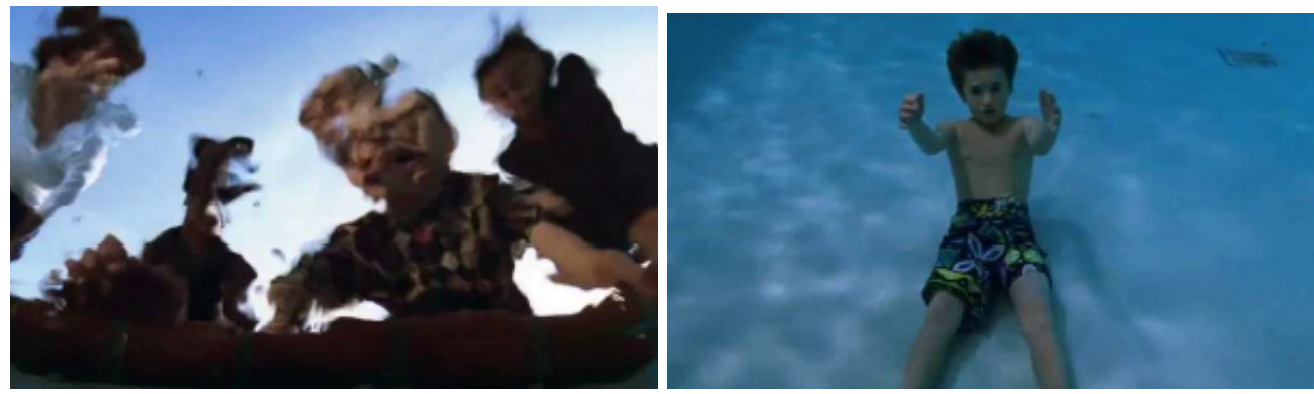

F. 3 y 4. Fotogramas de A. I. - Artificial Intelligence de Steven Spielberg (2001) (imágenes extraídas del DVD de la película)

Por otro lado, el agua como un elemento maligno y misterioso figura en Sphere de Barry Levinson (1998). Los protagonistas de este filme se topan con un submarino abandonado que porta en su interior una esfera enorme. La superficie del objeto extraño tiene una apariencia líquida y reflectante, parece un organismo vivo que piensa y tiene poderes paranormales. Los tripulantes ven alterada su percepción de la realidad y sufren cambios en su personalidad bajo la influencia de la esfera líquida. A consecuencia, el artefacto se convierte en el personaje central de la trama fílmica: el contacto con él desencadena todo tipo de acontecimientos y finalmente llegamos a suponer que representa una especie de portal que une diversas realidades, las distorsiona, incluso controla el tiempo material de la vida de los humanos. Podría considerarse un ser divino capaz de robar la existencia y el alma de un individuo al reflejar su rostro en la superficie especular. La apariencia propia de la esfera líquida destila el misterio y el peligro.

En What lies beneath Robert Zemeckis vincula el agua con el mundo de los espíritus. Claire, la protagonista tiene contacto con el fantasma de la mujer asesinada por su marido siempre a través del agua: ve los contornos inciertos de un cuerpo flotando en el estanque, un rostro en la bañera llena. La lluvia intensa evoca sus recuerdos bloqueados por el trauma recibido en un accidente del coche. La escena final se transcurre bajo el agua cuando el coche en que Claire huye de su marido se cae al lago y se sumerge rápidamente. Mientras los dos se hunden en las aguas oscuras, aparece la visión de la chica asesinada que de repente cobra vida, detiene al marido en su intento de escapar de la muerte y ayuda de esta manera a Claire a salir ilesa. Agua forma así un espacio habitado por los fantasmas que no 
encuentran la paz y buscan vengar sus muertes. La aparición acuática señala en este filme cada giro significativo en la narrativa, un recurso utilizado frecuentemente en la filmografía occidental.

Hablando de la simbología de agua como elemento misterioso que guarda oscuros secretos, es importante mencionar que el significado de agua como el habitáculo de los espíritus aparece a menudo en las películas de miedo de producción japonesa. A pesar de la vinculación a la tradición oriental, el elaborado imaginario del cine de miedo japonés se relaciona con la experimentación del medio acuático desde el punto de vista de un pueblo isleño constantemente amenazado a ser destruido por el elemento natural. Por consiguiente, en la tradición japonesa el agua se considera frecuentemente el cobijo de las almas de los difuntos, de poderosos espíritus ancestrales. Adquiere, en este sentido, una gran importancia las cualidades de la transparencia y la opacidad del líquido: las aguas transparentes se asocian con la perfección y la verdad absoluta y las turbias con el misterio, la desgracia y el mundo de los espíritus malignos.

Así, en Honogurai mizu no soko kara (Dark water) de Nakata Hideo (2002) una madre soltera se traslada con su hija a un nuevo apartamento donde empiezan a ocurrir cosas extrañas provocadas por el espíritu de una niña que murió ahogada en el depósito de agua del edificio. La experimentación del fantasma por parte de las protagonistas siempre es precedida o acompañada por la aparición de un líquido oscuro. La niña muerta se encuentra suspendida en el agua que simboliza un espacio entre el mundo de los vivos y de los muertos. El medio acuático es su nuevo hábitat y la vía que utiliza para llegar a encontrar la paz. El terror constante que siente la madre se expresa poderosamente a través del movimiento de líquido denso y amenazador que llena tanto la realidad como sus sueños. Finalmente la mujer se ahoga en él y pasa a formar parte del mundo de la niña muerta. El ciclo interrumpido de la vida se renueva por medio de este sacrificio de la madre.

Vemos aquí una alusión al agua como símbolo del subconsciente humano. Se podría interpretar que las oscuras aguas expresan la confusión psicológica provocada por el alejamiento progresivo de la sociedad japonesa de la 
tradición ancestral. El conocimiento milenario desaparece dejando desprotegido el alma de las personas, alterando la armonía de su existencia espiritual. Los cambios desencadenados por la globalización se ven, por tanto como una clara amenaza capaz de robar la identidad de las personas. La fluidez de la contemporaneidad destruye las bases de la vida de Japón creadas durante milenios. Al hilo de ello, si intentemos profundizar en la primera lectura que ofrecen las películas que hemos analizado en este apartado veremos alusiones al gran temor de la sociedad globalizada - la pérdida de la identidad.

En este sentido, Zigmund Bauman (2000) ofrece una metáfora muy potente para describir nuestro mundo actual atribuyéndole las propiedades de un líquido. El sociólogo polaco nombra la modernidad líquida, sociedades líquidas, identidades fluidas como conceptos base de la experiencia del mundo contemporáneo, negando así cualquier atisbo de la estabilidad social e identitaria. Todo nuestro entorno se transforma velozmente y nos exige a su vez un movimiento constante de la adaptación. El profesor Willi del IAE utiliza una curiosa metáfora para explicar esta idea de Bauman:

Cuando patinamos sobre hielo quebradizo nuestra seguridad depende de la velocidad. En el fondo, esa velocidad está dada por la liquidez del suelo. Lo mismo pasa en la vida: si no corremos, nos caemos y nos quedamos afuera de la última tecnología, nos quedamos sin trabajo o fuera de una moda. Parece ser que lo que nos queda es ir a toda velocidad para entrar en un ritmo que no nos permita reflexionar (cit. Pouiller, 2010, p.75).

El experto en política y filosofía del IAE opina que en estas circunstancias la noción de la libertad "líquida" adquiere grado negativo ya que pretende que el individuo se desprenda de cualquier atadura o compromiso. La situación que a primera vista promete una autonomía total de la autodefición, sin embargo, se agota en si misma encerrando al individuo en una espiral del movimiento constante en el esfuerzo de la adaptación. La inseguridad que provoca un entorno inestable no deja de inducir el deseo de encontrar un punto de anclaje para la identidad individual que reside en la conciencia colectiva de una nación o en la pertenencia a un colectivo determinado. En este sentido, las estrategias identitarias que se elabora el individuo para 
poder hacer frente a la liquidez del entorno, se difieren mucho de las aplicables en las circunstancias de la estabilidad. El lugar de origen ya no se podría considerarse un dato relevante en cuanto a la autodefinición subjetiva. Lo único determinante en este sentido es lo que uno hace. Willi puntualiza que el verdadero problema se manifiesta cuando la actividad se ve interrumpida por alguna circunstancia.

En definitiva, se crea la ilusión de la libertad mientras el individuo existe en la condición de "encarcelamiento incondicional” bajo la tensión de seguir el ritmo de un mundo en constante evolución. La situación angosta se desemboca en la imaginería apocalíptica tanto en el cine en particular, como en el arte en general. En relación a ello, el agua se sitúa como la expresión de la modernidad líquida y sus arrolladoras consecuencias vistas por el prisma de la construcción identitaria posiblemente gracias al grafismo de la metáfora que propone Bauman. De esta manera, se hace patente la existencia de una relación estrecha entre la angustia del individuo sumergido en un contexto social, económico, político y cultural líquido y el significado del agua como elemento amenazante y negativo en las obras cinematográficas, sobre todo de la producción occidental. Puntualizamos ciertas excepciones (cine japonés de horror) que adquieren sentido en el marco del mundo globalizado y multicultural.

\subsection{Fusión entre las dos tradiciones.}

El proceso de la globalización mundial fusiona las tradiciones y sus semióticas creando un sinfín de combinaciones. En 2011 sale a las pantallas la película de Terrence Malick, El árbol de la vida donde observamos una clara mezcla de los significados simbólicos de agua inherentes a las tradiciones tanto oriental como occidental. El elemento acuático se encuentra presente en cada secuencia tanto en la imagen como en el sonido: a pesar de que algunas escenas son ambientadas en la ciudad con sus grandes rascacielos de líneas rectas y colores grisáceos, se escucha en todo momento el sonido del mar como fondo. La vinculación entre la naturaleza, el Dios y el agua es determinante en el desarrollo de la historia que cuenta la película. 
Las tres nociones tienen connotaciones tanto positivas como negativas: la naturaleza bella y destructiva, el Dios misericordioso y despiadado, el agua como fuente de la vida y causante de la muerte. De esta manera, el lenguaje del filme combina diversos puntos de la semiótica de agua ofrecida por las tradiciones religiosas y filosóficas de todo el mundo.

Además, vista la argumentación de la divergencia entre las lecturas del símbolo acuático, nos gustaría puntualizar una teoría de la percepción primaria del medio líquido ofrecida por Adriano D’Aloia (2012) en su artículo Film in Depth. Water and Immersivity in the Contemporary Film Experience. El autor reflexiona sobre la visión del imaginario acuático en la pantalla por el prisma del conocimiento pre-cognitivo y pre-lingüístico. En su opinión cada espectador guarda en su memoria subconsciente la sensación de estar suspendido en el líquido dentro del útero materno. Antes de que entren en juego las alteraciones de la percepción por el condicionamiento cultural, la experiencia primaria del agua ofrece una lectura inmediata de la imagen percibida por el ojo. Como un ejemplo, podemos mencionar el final poético de The piano (Campion, 1993), la escena que participa de esta impresión esencial mostrando el cuerpo de la protagonista, Ada, flotando sobre su piano postrado en el fondo del mar. Oímos la voz de la chica recitando El poema del silencio de Thomas Hood:

There is a silence where hath been no sound,

There is a silence where no sound may be.

In the cold grave, under the deep deep sea. ${ }^{2}$

El sórdido e irremediable silencio del final y comienzo de la vida es evocado eficazmente por el sumergimiento en las aguas profundas del mar.

\section{Conclusiones}

Nuestra investigación parte de la hipótesis que relaciona la simbología de agua empleada en el cine con el pensamiento e el imaginario religioso perteneciente a diversas tradiciones, destacando las divergencias entre el

\footnotetext{
${ }^{2}$ Hay un silencio en el cual nunca hubo ningún sonido, hay un silencio donde no puede haber sonido. En la tumba fría, en las profundidades del mar profundo (La traducción es nuestra).
} 
pensamiento oriental y occidental. La diferencia marcada entre las dos cosmovisiones descritas en presente estudio se establece a partir de la manera de percibir el entorno natural. En este sentido, el Oriente habitualmente se percibe como la civilización que trata a la naturaleza con respeto filial y el Occidente la concibe como la fuente de los recursos.

Hemos podido comprobar que toda una serie de obras cinematográficas producidas en Rusia durante las últimas décadas participan de las ideas orientales siguiendo la tendencia que inicia Andrey Tarkovsky en los años 60 del siglo XX. Las aguas en los filmes del poetismo ruso o denominado cine intelectual simbolizan crecimiento espiritual y anuncian la reflexión sobre la reconstrucción identitaria en el periodo post-soviético. El barco aparece en el discurso en calidad del símbolo asociado al medio acuático representando la matriz, un lugar de gestación del yo renovado.

Por otro lado, el cine occidental se nutre del imaginario de cataclismo bíblico presentando una visión de agua como una fuerza destructiva. Este catastrofismo reinante se aprecia sobre todo en la producción hollywoodiense (Waterworld, 2012, etc.) También observamos que algunos filmes incluyen imaginario acuático que induce sensación de inquietud, peligro y misterio (Sphere, What lies beneath). En definitiva, el agua como elemento simbólico o un personaje de la trama tiene connotaciones negativas amenazando la integridad física o espiritual de los protagonistas. Trazamos paralelos entre este planteamiento y la teoría de la modernidad líquida de Zigmund Bauman que proclama la inestabilidad social e identitaria característica para el mundo contemporáneo. Asimismo, el proceso de la globalización pone en contacto diversas tradiciones que se fusionan creando un lenguaje simbólico híbrido, como observamos en la película de Terrence Malick.

En definitiva, el simbolismo de agua generado por diversas tradiciones culturales presenta un amplio abanico de posibilidades como recurso cinematográfico y seguirá suscitando interés en los cineastas de todo el mundo. 


\section{Referencias bibliográficas}

Bauman, Z. (2000). Modernidad líquida. Argentina: Fondo de la Cultura Económica.

Bubnova, T. (2003). Signo poético e identidad rusa en el cine de Tarkovski. Acta poética, 24, pp. 27-62.

D'Aloia, A. (2012). Film in Depth. Water and Immersivity in the Contemporary Film Experience. Acta Univ. Sapientiae, Film and Media Studies, 5. pp. 87-106.

Deleuze, G. (1984). La imagen-movimiento. Estudios sobre cine 1. Barcelona: Editorial Paidós.

Eliade, M. (1974). Tratado de historia de las religiones, Madrid: Ediciones Cristiandad S. L.

Graham, S. (2000). Chernukha and Russian Film. Studies in Slavic Culture, 1, 9-27.

Pouiller M. F. (2010). ¿Es posible vivir de una manera líquida? IAE, El valor humano en la empresa, 18, pp.74-76.

\section{Filmografía}

Bayona, J. A. (Director). (2012). Lo imposible. [Película]. Alicante: Ciudad de la Luz.

Campion, J. (Director). (1993). The Piano. [Película]. Nueva Zelanda, Australia: Jan Chapman Productions. Francia: Ciby 2000.

Emmerich, R. (Director). (2009). 2012. [Película]. Los Ángeles: Centropolis Entertainment.

Epstein, J. (Director). (1947). Le Tempestaire. [Película]. Francia: France Ilustration.

Khotinenko, V. (Director). (1995). Musulmanin [Musulmano]. [Película]. Moscú: Russian Film Committee.

Kirsanov, D. (Director). (1924). Menilmontant. [Película]. Francia : B\&W.

Levinson, B. (Director). (1998). Sphere [Sfera]. [Película]. EEUU: Warner Bors., Baltimore Pictures.

Malick, T. (Director). (2011). The tree of life [El árbol de la vida]. [Película]. EEUU: River Road Entertainment, Plan B Entertainment.

Nakata, H. (Director). (2002). Honogurai mizu no soko kara [Dark Water]. [Película]. Japón: Honogurai mizu no Soko kara Seisaku Iñaki, Kadokawa Shoten Publishing Co.

Petersen, W. (Director). (2000). The Perfect Storm. [Película]. EEUU: Warner Bros. 
Renoir, J. (Director). (1951). El río. [Película]. Francia, India: Oriental International Films.

Sokurov, A. (Director). (1978-1987). Odinokiy golos cheloveka [La voz solitaria del hombre]. [Película]. San Petersburgo: Lenfilm.

Sokurov, A. (Director). (1983). Skorbnoe bezchuvstvie [Dolorosa indiferencia]. [Película]. San-Petersburgo: Lenfilm.

Sokurov, A. (Director). (1988). Dni zatmeniya [Días de eclipse]. [Película]. San-Petersburgo: Lenfilm.

Sokurov, A. (Director). (1997). Mat y sin [Madre e hijo]. [Película]. SanPetersburgo: Lenfilm.

Sokurov A. (Director). (1989). Cpasi y sokhrani [Salva y protege]. [Película]. San Petersburgo: Lenfilm.

Spielberg, S. (Director). (2001). Artificial Intelligence. [Película]. Universal City: Amblin Entertainment. Santa Monica: The Kennedy/Marshall Company.

Storozheva, V. (Director). (2007). Puteshestvie s domashnimi zhivotnimi [Viaje con mascotas]. [Película]. Moscú: Slon, Profit.

Tarkovsky, A. (Director). (1966). Andrey Rublev. [Película]. Moscú: Mosfilm.

Tarkovsky, A. (Director). (1972). Solyaris. [Película]. Moscú: Mosfilm.

Tarkovsky, A. (Director). (1975). Zerkalo [Espejo]. [Película]. Moscú: Mosfilm.

Tarkovsky, A. (Director). (1979). Stalker. [Película]. Moscú: Mosfilm.

Tarkovsky, A. (Director). (Director). (1983). Nostalgia. [Película]. Roma: Opera film. Moscú: Sovinfilm.

Tarkovsky, A. (Director). (1986). Zhertvoprinoshenie [Sacrificio]. [Película]. Estocolmo: Instituto Cinematográfico Sueco. París: Argos Film.

Vigo, J. (Director). (1934). L'Atalante. [Película]. Neuilly-sur-Sein, Francia: Gaumont.

Zemeckis, R. (Director). (2000). What Lies Beneath. [Película]. Novato, California: ImageMovers.

Zvyaginzev, A. (Director). (2003). Vozvraschenie [El regreso]. [Película]. Moscú: RENTV.

Cómo citar: Borisova, A. (2014). "Simbolismo de agua en el cine: entre el orientalismo poético ruso y el catastrofismo occidental". Fotocinema. Revista científica de cine $y$ fotografía, 9, pp. 255-281. Disponible: http://www.revistafotocinema.com/index.php?journal=fotocinema 